\title{
THE PHOTOMETRY OF THERAPEUTIC LAMPS.
}

\author{
I. RELATION OF PHOTO-ELECTRIC POWER OF LAMPS TO THEIR \\ BACTERICIDAL POWER. \\ II. COMPARISON OF THE EMISSION OF VARIOUS ULTRA-VIOLET \\ SOURCES.
}

\author{
By HARRY D. GRIFFITH, B.A., CAMb. \\ Assistant in Natural Philosophy and Carnegie Teaching Fellow \\ in the University of Aberdeen \\ AND \\ JOHN S. TAYLOR, M.B., Ch.B., D.P.H., ABerd. \\ Assistant Medical Officer of Health, City of Aberdeen. \\ (With One Chart.)

\section{The Relation of the Bactericidal to Photo-electric ACTIVITY OF VARIOUS SOURCES OF ULTRA-VIOLET RADIATION.}

THE following paper gives some results of a series of experiments on the bactericidal power of various sources of ultra-violet radiation. The "power" of the source was in each case measured by the quartz-cadmium photo-electric cell described by the authors (1925), and it is shown that very definite and practically useful correlations exist between the cell reading and this typical abiotic action.

Method. Cultures were prepared by spreading a uniform layer of an emulsion of the bacteria to be investigated on agar in Petri dishes. The opaque covers of the dishes were provided with two natural quartz windows through which the exposures were made, two separate exposures being generally possible on one plate. After exposure the cultures were incubated and the resultant distribution of colonies studied. The bacteria employed were Staphylococcus albus in the main series of experiments, and the end point was found to be surprisingly definite. Streptococcus scarlatinae was also used in a few cases, but with inferior results as regards sharpness of end point. The lethal exposure could be determined with an error not exceeding 10 per cent. Whole series of experiments were carried out using as far as possible one emulsion of bacteria, spread at the same time. Where this was not possible, the relative susceptibility of the cultures used was estimated and any small difference found was allowed for in comparing results with those obtained from another emulsion.

It will be seen that the lethal exposures necessary were generally of the order of 3 or 4 minutes at 3 feet from the lamps, going up to a maximum of 9 minutes for the weakest lamp. It was probable, therefore, that the lethal effect of direct heating by the absorption of radiation was negligible. This 
was confirmed when it was ascertained that the rise of temperature as measured by a thermopile immersed in the culture medium under the quartz window was of the order of $3^{\circ} \mathrm{C}$. after 10 minutes' exposure in the case of the 800 watt carbon arc, where it would be greatest.

Control experiments showed that there was no sign of activation of the culture medium consequent upon irradiation, as would be expected from the work of Coblentz and Fulton (1925) who found activation only with exposures very much greater than those used in our experiments.

\section{Calculation of Results.}

The photo-electric power is obtained as described in our previous paper (1925). Briefly, it involves determination of three quantities-the distance from lamp to cell $(D)$ inches, the time of discharge of the cell through the standard range ( $T$ secs.), and the size of the diaphragm used $(A \mathrm{~mm}$.). The photo-electric power is then given by

$$
P=\underset{100}{1} \times \frac{D^{2}}{T} \times\left(\frac{22}{A}\right)^{2}
$$

The units in which the result is expressed are then arbitrary, analogous to the candle power of an ordinary source. The authors have become accustomed to refer to them as "U.-V. Candles."

The bactericidal power is defined in terms of that of a mercury arc, which was known to be in steady running condition. Its killing time on a culture distant 3 feet was found to be 4.75 minutes, and its bactericidal power taken as 32 units, to agree with the "ultra-violet candle power" measured by the cell. Then, if another lamp $D$ feet away kills in $T$ minutes, the bactericidal power of that lamp is defined as

$$
32\left(\frac{D}{3}\right)^{2} \times \frac{4 \cdot 75}{T}=16 \cdot 9 \frac{D^{2}}{T}
$$

The methods used depend on two fundamental assumptions-that the lethal action is proportional to the time of exposure, and that the killing time is proportional to the square of the distance from the lamp. These are taken as verified to sufficient approximation by the results of Coblentz and Fulton (1925) and of Leonard Hill (1923), over the range of light intensities (1:2) involved in this work.

The bactericidal and photo-electric powers agree by definition for the standard mercury lamp; results will now be given showing how far there is agreement in other types of lamp.

$\begin{array}{cccccc}\text { Watts } & \begin{array}{c}\text { Distance } \\ \text { (feet) }\end{array} & \begin{array}{c}\text { Killing time } \\ \text { (mins.) }\end{array} & \begin{array}{c}\text { Photo-electric } \\ \text { power }\end{array} & \begin{array}{c}\text { Bactericidal } \\ \text { power }\end{array} \\ \text { Carbon } & 4500 & 12 & 3 \cdot 5 & 550 & 690 \\ \text { ", } & 700 & 3 & 8 \cdot 5 & 15 & 18 \\ \text { Tungsten } & - & 3 & 9 \cdot 75 & 14 & 15 \\ \text {," } & 364 & 3 & 2 \cdot 75 & 62 & 55 \\ \text { Mercury A } & 175 & 3 & 6 \cdot 5 & 20 & 23 \\ \text {," B } & 291 & 3 & 4 \cdot 5 & 40 & 34 \\ \text { Iron } & 358 & 3 & 4 \cdot 75 & 32 & 32 \\ & 400 & 3 & 5 \cdot 75 & 22 & 26\end{array}$


From these results it will be seen that in lamps of powers varying in the ratio 1 : 40 and of very different construction, the bactericidal activity follows the photo-electric activity in the quartz-cadmium cell within the limits of $1: 1 \cdot 3$.

In a second series of experiments, the bactericidal activity of sources was investigated by finding how far a culture has to be placed from the lamp to be sterilised in 4 minutes.

$\begin{array}{lccccc} & \text { Watts } & \begin{array}{c}\text { Distance } \\ \text { (ins.) }\end{array} & \begin{array}{c}\text { Killing time } \\ \text { (mins.) }\end{array} & \begin{array}{c}\text { Photo-electric } \\ \text { power }\end{array} & \begin{array}{c}\text { Bactericidal } \\ \text { power }\end{array} \\ \text { Carbon } & 700 & 37 & 4 & 37 & 41 \\ \text { Tungsten } & 380 & 69 & 4 & 120 & 140 \\ \text { Iron } & 400 & 26 & 4 & 21 & 20 \\ \text { Mercury } & 410 & 160 & 4 & 150 & 158\end{array}$

Experiments are in progress designed to elucidate the full nature of this agreement by systematic investigation of the relation of reaction to wavelength (for radiation of definite energy, as measured by a bolometer) both in the case of the photo-electric action and that of the bactericidal action, in extension of the experiments of Browning and Russ (1917). The work of Clarke and Watters (1922), and of Osgood (1924), make it clear that this agreement was likely to exist.

(Incubation for half-an-hour after spreading increases susceptibility to ultra-violet about 4.5 times.)

\section{Comparison of Various Sources of Radiation.}

The following results give the "ultra-violet candle powers" of various sources as measured by the quartz-cadmium cell.

\section{Quartz-Mercury Arcs.}

Quantitative measurements of the total ultra-violet emission (between $450 \mu \mu$ and $170 \mu \mu$ ) of quartz-mercury arcs have been made by Coblentz (1921), but our measurements, which are in general agreement with his, are of interest as they refer to the narrower region of the ultra-violet $(350 \mu \mu$ to $220 \mu \mu)$ upon the biotic effects of which attention is at present mainly centred. In every lamp tested there are temporary large and complex variations of ultra-violet emission just after the lamp has been switched on, and to a less extent when the current is altered. These involve a number of factors, including temperature changes in the burner and series resistance of the lamp, which require 20 minutes or so to adjust themselves, after which the emission reaches a steady value. In each case this steady state was reached before taking observations.

Variation of ultra-violet emission with watts in-put. Type $A$.

$\begin{array}{cccc}\text { Amps. } & \text { Watts } & \text { U.-V. power } & \text { Line volts } \\ 1.5 & 162 & 15 & 170 \\ 2 \cdot 0 & 212 & 21 & 188 \\ 2 \cdot 3 & 234 & 23 & 196 \\ 3 \cdot 0 & 291 & 35 & 220\end{array}$


Thus a decrease of line-voltage of 5 per cent. causes a decrease of 14 per cent. in the emission of the lamp.

This is in close agreement with the result obtained by Coblentz (1921) using the thermopile and filters, as mentioned above. Measurements were also made by Henri (1911) using the lethal effect on Bacillus coli as his measure of the ultra-violet emission, and show a somewhat greater variation than was found in our experiments.

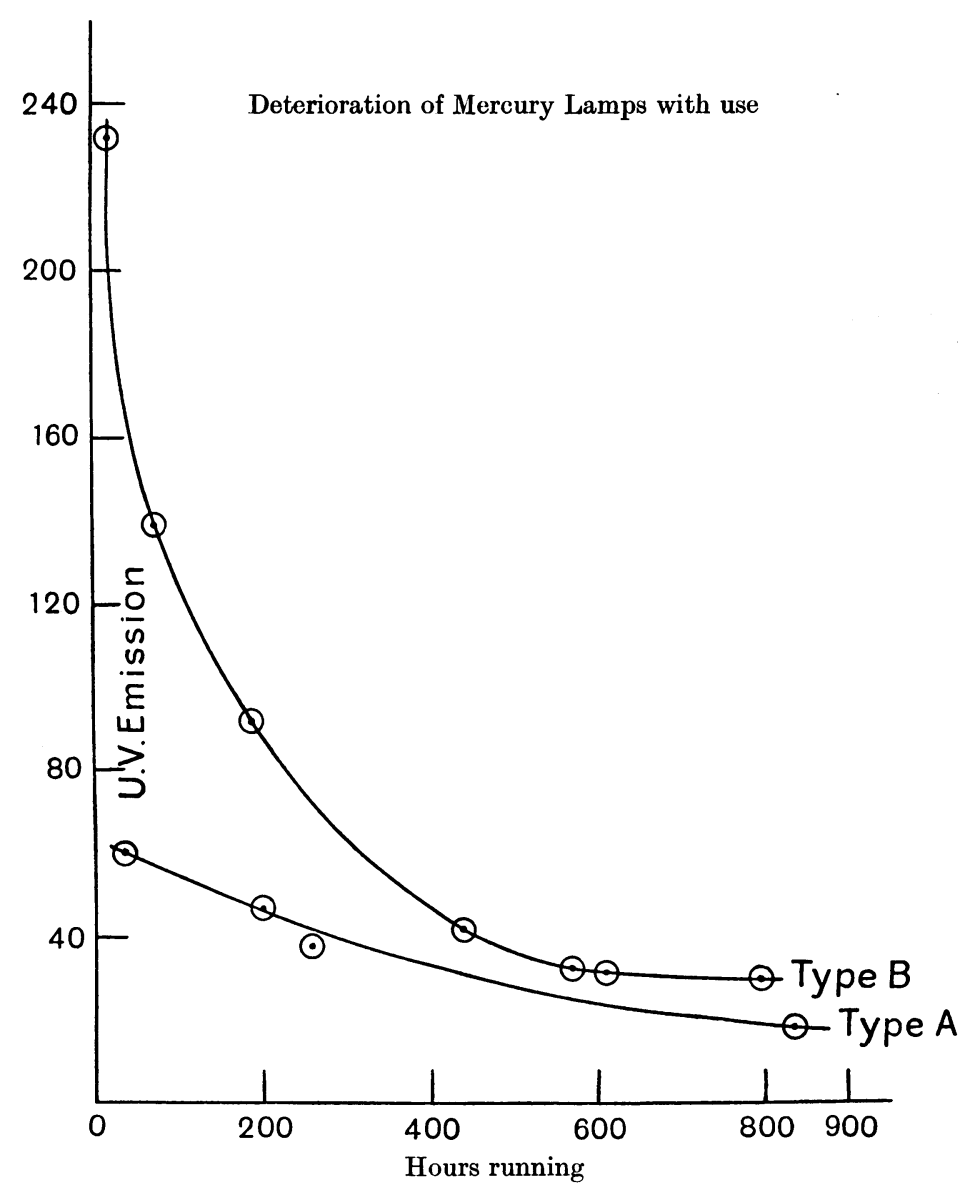

Deterioration of Lamps with Use.

Two types of lamp have been studied: (1) a Hanau "vacuum" lamp B, taking 3 amps. at 126 volts across the tube, and (2) a K.B.B. "atmospheric" lamp A, taking 3 amps. at 97 volts. Both lamps were running under the conditions laid down by their makers, for hospital use.

It is seen that the vacuum lamp, though initially 4 times as powerful as the atmospheric type, deteriorates far more rapidly. Measurements made by Coblentz (1921) and by Moss and Knapp (1925) by a photo-chemical method 


$\begin{array}{cc}\overbrace{\text { Hours used }} & \text { Uype A } \\ \frac{\overline{15}}{200} & \overline{56} \\ \frac{56}{840} & \overline{44} \\ - & \frac{-}{15}\end{array}$

\begin{tabular}{cc}
\multicolumn{2}{c}{ Type B } \\
Hours used & U.-V. emission \\
10 & 230 \\
70 & 138 \\
190 & 90 \\
390 & 66 \\
450 & 40 \\
580 & 32 \\
800 & 29
\end{tabular}

agree with the results we find for lamp A. It will be apparent that this very rapid deterioration of Type B makes it a matter of some difficulty to control dosage when the lamp is new.

\section{Carbon Arcs.}

A detailed study of this arc was made by Lindemann (1906) for small arcs, by a photo-electric method, using a copper oxide cathode which would be mainly sensitive to radiation shorter than $250 \mu \mu$. It is implicit in his work that a small arc is a less powerful source of ultra-violet radiation than a longer one consuming the same electrical energy.

This question has also been studied by Angus (1925) in regard to the lethal effect of the arc on Paramecium, and he finds that the effective ultra-violet emission depends only on the power consumed in the arc, and not at all on its length, using arcs consuming about 1700 watts and of lengths varying from 10 to 50 millimetres.

The results given below show that this important discrepancy is due to the fact that the arcs used by Lindemann were low-power arcs to which the results of Angus, obtained with high-power arcs, do not apply. In our experiments the watts consumed in the arc were kept as far constant as possible by adjusting a series resistance while the arc length was varied. The length of the arc could be found from the size of its magnified image formed by a lens on a screen, and kept constant by hand-feeding while watching the image. The carbons were in line in the type of arc used, and the emission was measured from a point level with the arc, about 10 feet away.

$\begin{array}{ccc}\text { Arc length mm. } & \text { Watts } & \text { U. } \text { V. power } \\ 3 \cdot 4 & 756 & 14 \\ 6 \cdot 8 & 776 & 23 \\ 10 \cdot 2 & 756 & 31 \\ 13 \cdot 6 & 766 & 35 \\ 17 \cdot 0 & 756 & 36\end{array}$

Thus in the cases studied, the law found by Angus is seen to hold for arcs longer than about $12 \mathrm{~mm}$. but not in the case of short arcs. Work is in hand to investigate the mechanism of this difference by photographing arcs through an apparatus resembling a spectro-heliograph, by which the distribution in the arc of radiation of any individual wave length can be determined.

The relation of ultra-violet output to electrical energy supplied is given by Angus (1925) and in our previous paper (1925). 


\section{Carbon Arcs in Series.}

When arcs have to be run from a 220 volt circuit, it seems likely that increased efficiency might be obtained by connecting several arcs in series with a control resistance smaller than that which any one of them alone would require. The following results show that this method has its limitations.

Several hand-fed arcs were connected in series to the 220 volt supply, through a variable control resistance, and readings were taken of the total "ultra-violet candle power" of the composite source. The control resistance was cut down step by step, the arc length being set in each case so as to keep the current at 11 amps., so that the power taken from the mains was always 2200 watts.

\begin{tabular}{cccccccc}
$\begin{array}{c}\text { Number } \\
\text { of ares }\end{array}$ & $\begin{array}{c}\text { External } \\
\text { resist. } \\
\text { ohms }\end{array}$ & $\begin{array}{c}\text { Watts in } \\
\text { arcs }\end{array}$ & $\begin{array}{c}\text { Total } \\
\text { U.-V. cand. }\end{array}$ & $\begin{array}{c}\text { Total } \\
\text { length } \\
\text { mm. }\end{array}$ & $\begin{array}{c}\text { Watts per } \\
\text { arc }\end{array}$ & $\begin{array}{c}\text { U.-V. cand. } \\
\text { per arc }\end{array}$ & $\begin{array}{c}\text { Length } \\
\text { per arc } \\
\text { mm. }\end{array}$ \\
3 & $5 \cdot 1$ & 1800 & 29 & 15 & 600 & 10 & 5 \\
3 & $4 \cdot 2$ & 1840 & 37 & 18 & 613 & 12 & 6 \\
3 & $3 \cdot 5$ & 1940 & 50 & 20 & 645 & 17 & 7 \\
3 & $2 \cdot 0$ & 2068 & & & Arcs unstable & & \\
2 & $8 \cdot 3$ & 1276 & 42 & 14 & 638 & 21 & 7 \\
2 & $5 \cdot 1$ & 1540 & 69 & 24 & 770 & 35 & 12 \\
1 & $15 \cdot 0$ & 680 & -25 & 11 & - & - & - \\
\hline 1 & $12 \cdot 0$ & 770 & -35 & -16 & - & - & - \\
1 & $9 \cdot 7$ & 1100 & 52 & 22 & - & - & -
\end{tabular}

These results show that as much ultra-violet emission can be got from one suitably designed (long) arc as from a group of several arcs in series taking the same electrical power from the mains (2200 watts). The reason for this appears in column 5, the total length of flame compatible with stable working being about the same whether it occurs in one single arc, or in three in series; so that, in so far as a short arc is less efficient than a long one taking the same power, subdivision of the flame would be expected to result in loss of efficiency.

This problem was suggested by the results of measurements on a commercial therapeutic lamp consisting of four short arcs in series with handfeeding, and series resistance 9 ohms. It took 13 amps. at 220 volts (2860 watts) in all, and gave 13 units of ultra-violet emission; whereas one single arc taking 11 amps. (2200 watts) gave up to 52 units.

In the case of higher power arcs, the above conclusions do not necessarily apply, since here, efficiency is independent of arc length. Also, their individual automatic regulators may enable the total flame length of a group in series to be more than that possible for one single arc. But here other factors enter which make it usual in practice to work them in parallel from a low voltage supply.

The total radiation from the composite arc is far greater than that from a single arc taking the same power from the mains, so that the heating effect on a patient is much greater. Thus, in the case of the 2860 watt composite 
arc-lamp mentioned above, exposure of the forearm for 22 minutes at 20 inches caused more heating than could be comfortably endured. The erythema produced was practically the same as that following an exposure of 10 minutes at the same distance from a single arc (2200 watt) giving 35 units; this exposure could have been very greatly prolonged without any discomfort.

$$
\text { "Cinema" Type Arc. }
$$

The emission from an arc in which the carbons are at right angles, so that the crater is wholly exposed, was measured from a point facing the crater and level with it. It was found to be sensibly the same as that of an arc in which the carbons are in line, which consumed the same electrical power.

\begin{tabular}{|c|c|c|}
\hline \multicolumn{3}{|c|}{ Tungsten Arcs (electrodes in line). } \\
\hline Length (mm.) & Watts & U.-V. emission \\
\hline $6 \cdot 8$ & 326 & 77 \\
\hline $13 \cdot 6$ & 348 & 100 \\
\hline $20 \cdot 4$ & 360 & 102 \\
\hline $6 \cdot 8$ & 206 & 19 \\
\hline \multicolumn{3}{|c|}{ Iron Arcs (electrodes in line). } \\
\hline Length (mm.) & Watts & U.-V. emission \\
\hline $5 \cdot 0$ & 322 & 15 \\
\hline $13 \cdot 6$ & 400 & 22 \\
\hline $20 \cdot 4$ & 498 & 23 \\
\hline $34 \cdot 0$ & 460 & 23 \\
\hline
\end{tabular}

This arc has been used successfully as a rough standard of ultra-violet emission (23 ultra-violet candle power). The electrodes used are rods of mild steel, diam. $6.4 \mathrm{~mm}$., and the arc length is set to a definite value by use of a lens and screen as described above. The button of molten iron formed at the poles must be chipped away before the arc is restarted.

We take this opportunity of acknowledging our indebtedness to Dr J. Parlane Kinloch, Medical Officer of Health, Aberdeen, for suggesting this research into the Photometry of Therapeutic Lamps and for affording facilities for the work.

\section{REFERENCES.}

Angus (1925). Proc. Roy. Soc. B. xcvirI. 400.

Browning and Russ (1917). Ibid. B. xc. 33.

Clarke and Watters (1922). J. Roent. Soc. xviri. 119.

Coblentz (1921). Amer. J. Electrotherap. and Radiol. xxxix. 395.

Coblentz and Fulton (1925). Bull. Bureau of Standards, 495.

GRIFFITH and TAYLOR (5. xII. 1925). Lancet, II. 1905.

Henri (1911). Compt. Rend. cLII. 265.

Hill (1923). Proc. Roy. Soc. B. xCv. 163.

KnapP (1925). J. Soc. Chem. Ind. xuIv. 37.

Lindemann (1906). Ann. der Physik, xix. 807.

OsGood (1924). Proc. Roy. Soc. Edinh. xuIv. 8.

(MS. received for publication 27. III. 1926.-Ed.) 


\section{INDUSTRIAL MEDICINE.}

Of recent years there has been a steady increase in the number of large industrial concerns in this country employing medical men and women to advise their management regarding factory hygiene, the prevention of avoidable accidents, illness, and industrial diseases, and to assist in promoting the general well-being of the staff and workpeople. This increase, and the example set in America for some years past, led to the formation last year of "THE COUNCIL OF INDUSTRIAL MEDICINE" as an association of British industrial physicians and surgeons. This Council has already over 40 members and meets regularly on the fourth Friday in each month at 12, Stratford Place, London, W. 1, when discussions take place on the various problems confronting this comparatively new branch of preventive medicine. The Council is also the British section of the International Congress on Industrial Accidents and Diseases which held its fourth meeting in Amsterdam last autumn. It is hoped that the International Congress of Industrial Acts and Diseases will at some future date hold a meeting in London. The actual date will be fixed by the International Committee. The Council of Industrial Medicine is anxious to co-operate with all British medical practitioners (at home and abroad) who are specially engaged in Industrial Medicine. The executive are well aware that there are still a number of medical practitioners in Great Britain giving general or special medical services to industrial concerns with whom so far it has not succeeded in getting in touch and will be grateful if any such will write to the Secretary, Council of Industrial Medicine, Federation of Medical and Allied Services, 12, Stratford Place, London, W. 1.

Yours faithfully,

D. A. COLES, Chairman.

(Letter received for publication 26. v. 1926.-Ed.) 